\title{
Performance report cards increase adenoma detection rate
} (이요 $\odot$

\author{
Authors \\ Institutions \\ 1 Division of Gastroenterology, Department of Medicine, \\ Western University, London, Ontario, Canada \\ 2 Department of Medicine, Western University, London, \\ Ontario, Canada \\ 3 Lawson Health Research Institute, London, Ontario, \\ Canada \\ 4 South West Regional Cancer Program, Cancer Care \\ Ontario, Ontario, Canada \\ 5 Robarts Clinical Trials, London, Ontario, Canada
}

Michael Sai Lai Sey ${ }^{1}$, Andy Liư ${ }^{2}$, Samuel Asfaha ${ }^{1,3}$, Victoria Siebring ${ }^{4}$, Vipul Jairath ${ }^{1,5}$, Brian Yan $^{1}$

submitted 18.11 .2016

accepted after revision 10.4 .2017

\author{
Bibliography \\ DOI https://doi.org/10.1055/s-0043-110568 | \\ Endoscopy International Open 2017; 05: E675-E682 \\ (c) Georg Thieme Verlag KG Stuttgart · New York \\ ISSN 2364-3722
}

Corresponding author

Michael Sey, MD MPH FRCPC, Assistant Professor of

Medicine, Western University, London Health Sciences

Centre, 800 Commissioners Rd. E., London, ON, Canada,

N6A 5W9

Fax: 519-667-6820

msey2@uwo.ca

\section{ABSTRACT}

Background and study aims Adenoma detection rate (ADR) is an important measure of colonoscopy quality, as are polyp, advanced ADR, and adenocarcinoma detection rates. We investigated whether performance report cards improved these outcome measures.

Patients and methods Endoscopists were given report cards comparing their detection rates to the institutional mean on an annual basis. Detection rates were evaluated at baseline, 1 year after report cards (Year 1), and 2 years after report cards (Year 2). Endoscopists were unaware of the study and received no other interventions. The primary outcome was ADR and secondary outcomes were polyp detection rate (PDR), advanced $A D R$, and adenocarcinoma detection rate. Multivariate regression was performed to adjust for temporal trends in patient, endoscopists, and procedural factors.

Results Seventeen physicians performed 3,118 screening colonoscopies in patients with positive FOBT or family history of colon cancer. The ADR increased from $34.5 \%$ (baseline) to $39.4 \%$ (Year 1 ) and $41.2 \%$ (Year 2) $(P=0.0037)$. The PDR increased from $45 \%$ (baseline) to $48.8 \%$ (Year 1) and $51.8 \%$ (Year 2) $(P=0.011)$. There was no significant improvement in advanced ADR or adenocarcinoma detection rates. On multivariate analysis, the ADR increased by $22 \%$ in Year $1(P=0.03)$ and $30 \%$ in Year $2(P=0.008)$. Among physicians with a baseline $A D R<25 \%$, improvement in ADR was even greater, increasing 2.2 times by the end of the study $(P=0.004)$. Improvements in ADR were not correlated with specialty although gastroenterologists were $52 \%$ more likely to find an adenoma than general surgeons.

Conclusions Annual performance report cards increased adenoma detection rates, especially among physicians with low $A D R<25 \%$.

\section{Introduction}

Colon cancer is the second leading cause of cancer related deaths [1]. The sequence between adenoma to adenocarcinoma takes on average 10 years and can be prevented by polypectomy [2]. Numerous observational studies have reported reduced colorectal cancer mortality with the performance of colonoscopies and randomized clinical trials are underway [311]. Currently, colonoscopy is one of the major forms of colon cancer screening along with fecal testing [12].
Quality assurance is an integral part of an effective screening colonoscopy program. Adenoma detection rate (ADR) has emerged as one of the most important quality indicators. ADRs less than $20 \%$ have been associated with development of interval colon cancer after a screening colonoscopy $[13,14]$. As a result, recent guidelines recommend an $A D R \geq 25 \%$ [15]. However, there is considerable variation in the ADR between endoscopists $[16,17]$. Numerous interventions to improve the $A D R$, such as increased withdrawal time, enhanced inspection techniques, and/or educational interventions have been largely 
ineffective [18]. In this study, we sought to determine the effect of performance report cards on the ADR over a 3-year period.

\section{Patients and methods}

\section{Study design}

The study was conducted at St. Joseph's Health Care, an academic hospital affiliated with Western University (London, Ontario, Canada), between April 1, 2012 and Mar 31, 2015 as a part of a colonoscopy quality assurance initiative through the ColonCancerCheck ${ }^{\mathrm{TM}}$ (CCC) program of the Southwestern Ontario Regional Cancer Program and Cancer Care Ontario. The CCC was the first programmatic provincial colon cancer screening program in Canada, whereby average risk individuals aged 50 to 75 are encouraged to have biennial fecal occult blood testing (FOBT). All tests are processed at CCC approved labs using Hemoccult II Sensa (Beckman Coulter, Mississauga, Canada). Those with positive tests are then referred for colonoscopy. Patients with a family history of colon cancer in a first-degree relative are considered "high risk" and referred directly for colonoscopy. Thus, patients included in this study were those with either positive FOBT or a family history of colon cancer in a firstdegree relative having their first colonoscopy. Colonoscopies completed on symptomatic patients, average risk screening, or surveillance for colorectal neoplasm/polyps were excluded. All endoscopists involved in the program were board-certified gastroenterologists or general surgeons who performed at least 200 colonoscopies each year for any indication. Residents and fellows were not involved in any of the procedures. The protocol was approved by the university's Research Ethics Board.

Beginning on April 1, 2012, physicians were required to complete a colonoscopy reporting tool for all colonoscopies documenting the procedural indication, bowel preparation quality, cecal intubation, gross findings including detection of polyp(s), interventions completed, and immediate adverse events. Bowel preparation quality was rated using an ordinal scale as follows: good (mucosa seen throughout), fair (liquid contents, exam adequate), and poor (solid contents, exam compromised). The decision to use a simple ordinal scale was made by Cancer Care Ontario due to the lack of a standardized bowel preparation score used throughout the province. The tool was completed immediately after each procedure and participation was mandatory. In patients who were identified as having at least 1 polyp removed, histological information was manually reviewed to determine the polyp type. Because the quality assurance program was centered on programmatic colonoscopy screening, and due to the very high number of annual colonoscopies completed at the center, histology was not reviewed for other indications.

The study was divided into 3 phases. Between April 1, 2012 and March 31, 2013 (Baseline), physicians were not aware that the data from the colonoscopy reporting tool would be used to generate report cards. Personalized report cards were issued in April 2013 documenting a physician's cecal intubation rate, preparation quality, ADR, polyp detection rate (PDR), advanced
ADR, adenocarcinoma detection rate, and perforation rate compared to the institutional mean. A second report card was issued in April 2014. The period between April 1, 2013 and March 31, 2014 defined Year 1 and the period between April 1, 2014 and March 31, 2015 defined Year 2. Report cards were confidential and not shared with anyone other than the individual physician. There were no interventions other than the report cards. In addition, physicians were not aware of the study during the data collection period.

\section{Outcome definitions}

ADR was chosen as the primary outcome and defined as the proportion of patients undergoing colonoscopy with 1 or more adenomas confirmed histologically. Secondary outcomes included PDR, advanced ADR, and adenocarcinoma detection rate. PDR was defined as the proportion of patients undergoing colonoscopy with 1 or more polyps of any histology. An advanced adenoma was defined as having any of the following: $\geq 1 \mathrm{~cm}$ in diameter, villous histology, or high-grade dysplasia.

\section{Statistical analysis}

Individual patient level data were collected prospectively for each procedure. Crude analyses to compare the ADR, PDR, advanced $A D R$, and adenocarcinoma detection rates between baseline and Year 1 and baseline and Year 2 were performed using analysis of variance and pairwise comparisons. A Bonferonni correction was deemed unnecessary because the comparisons were only between 3 groups [19]. Multivariate logistic regression using generalized estimating equations was performed to adjust for patient (indication, age, gender) and procedural (physician specialty, bowel preparation quality, and cecal intubation) factors, which were defined a priori based on subject knowledge rather than empiric methods $[15,16,20]$. Given that ADR may differ for colonoscopies performed for positive FOBT and family history, we tested for effect modification by procedure indication. Furthermore, we examined for effect modification by specialty (gastroenterology versus general surgery), and baseline ADR ( $<25 \%$ versus $\geq 25$ ) using interaction terms. The cut off for baseline ADR was chosen to be $25 \%$ based on current targets recommended by recent guidelines [15]. A 2 -sided $P$ value $<0.05$ was considered significant. All statistical analyses were performed with Stata 14.0.

\section{Results}

Between April 1, 2012 and March 31, 2015, 17 physicians (11 gastroenterologists, 6 general surgeons) performed 3,118 colonoscopies on patients with a family history of colorectal cancer $(76.6 \%)$ or a positive FOBT $(23.4 \%)$ ( $\downarrow$ Table 1$)$. The mean (SD) patient age was 58.6 (10.5) and 59.8\% were female. Bowel preparation quality was rated as good, fair, and poor in $89.3 \%$, $8.6 \%$, and $2.1 \%$, respectively. Cecal intubation was successful in $96.6 \%$ of patients.

On crude analysis, ADR improved from a baseline of $34.5 \%$ to $39.4 \%$ in Year $1(P=0.0152)$ and to $41.2 \%$ in Year $2(P=$ 0.0016) ( $\triangleright$ Fig. 1 and $\triangleright$ Table 2). The increase in ADR between Year 1 and Year 2 was not statistically significant $(P=0.33)$. The 
- Table 1 Characteristics of 3,118 patients undergoing colonoscopies during the study period.

\begin{tabular}{|l|l|}
\hline Age-mean (SD) & $58.6(10.5)$ \\
\hline Female-no. (\%) & $1864(59.8 \%)$ \\
\hline Indication-no.(\%) & $2388(76.6 \%)$ \\
\hline - Family history of colon cancer & $730(23.4 \%)$ \\
\hline - Positive FOBT & \\
\hline Bowel preparation quality & $2,784(89.3 \%)$ \\
\hline - Good & $269(8.6 \%)$ \\
\hline - Fair & $65(2.1 \%)$ \\
\hline - Poor & \\
\hline Cecal intubation & $3,012(96.6 \%)$ \\
\hline - Yes & $94(3.0 \%)$ \\
\hline - No & $12(0.4 \%)$ \\
\hline - Not applicable ${ }^{1}$ & \\
\hline${ }^{1}$ Includes cases such as obstructing tumor and altered surgical anatomy \\
\hline
\end{tabular}

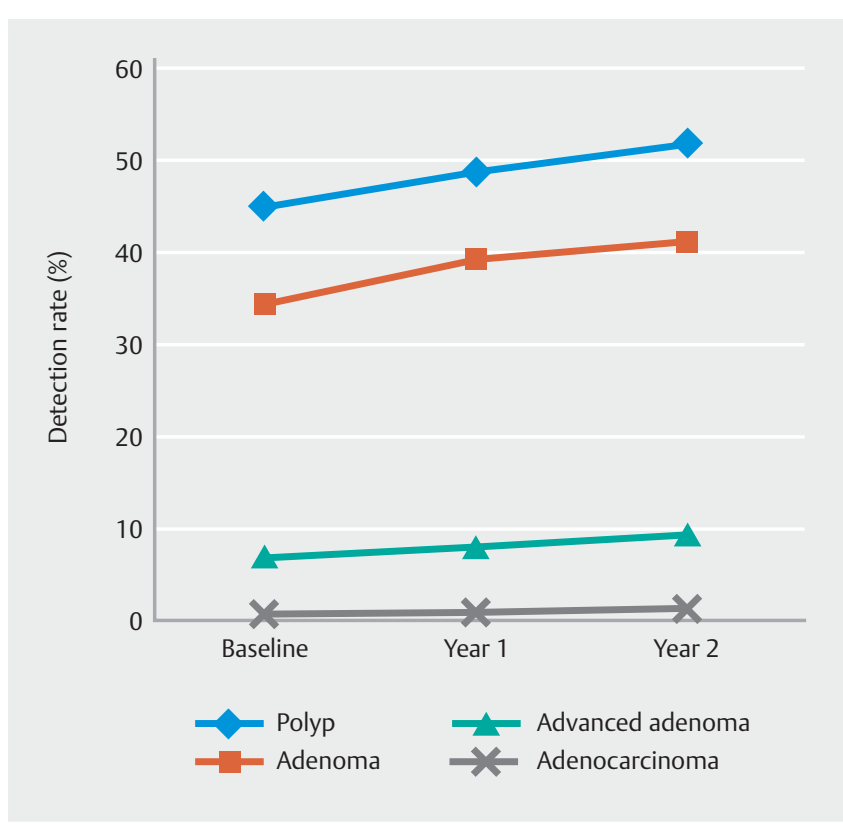

- Fig. 1 Detection rates by year.

- Table 2 Crude analysis of adenoma, polyp, advanced adenoma, and adenocarcinoma detection rate by year.

\begin{tabular}{|c|c|c|c|c|c|c|}
\hline & \multicolumn{3}{|l|}{ Detection rate-no. (\%) } & \multicolumn{3}{|l|}{$P$ value } \\
\hline & Baseline $(n=1,133)$ & Year $1(n=1,172)$ & Year $2(n=813)$ & Global & Year $1^{1}$ & Year $2^{1}$ \\
\hline Adenoma detection rate & $391(34.5 \%)$ & $462(39.4 \%)$ & $338(41.2 \%)$ & 0.0037 & 0.0152 & 0.0016 \\
\hline Polyp detection rate & $510(45.0 \%)$ & $572(48.8 \%)$ & $421(51.8 \%)$ & 0.0113 & 0.0684 & 0.0032 \\
\hline Advanced adenoma detection rate ${ }^{2}$ & $78(6.9 \%)$ & $95(8.1 \%)$ & $76(9.4 \%)$ & 0.14 & 0.28 & 0.05 \\
\hline Adenocarcinoma detection rate & $8(0.7 \%)$ & $10(0.9 \%)$ & $10(1.2 \%)$ & 0.4721 & 0.7082 & 0.2271 \\
\hline
\end{tabular}

PDR increased from a baseline of $45 \%$ to $48.8 \%$ in Year 1 (0.0684) and to $51.8 \%$ in Year $2(P=0.0032)$. The advanced ADR and adenocarcinoma rates improved each year but did not reach statistical significance.

On multivariate analysis controlling for patient age and gender, physician specialty, indication, bowel preparation quality, and cecal intubation, ADR increased by $22 \%$ in Year 1 (OR $1.22,95 \% \mathrm{Cl} 1.02-1.45, \mathrm{p}=0.03$ ) and $30 \%$ in Year 2 (OR 1.30, $95 \% \mathrm{Cl} 1.07-1.58, P=0.008)$ compared to baseline ( $>$ Table 3 ) (see $>$ Supplement for model details). The effect of the report card intervention on the ADR did not differ based on the indication for colonoscopy (interaction term $P$ value $>0.05$ ). However, there was evidence of effect modification by baseline $A D R$ when tested with an interaction term, indicating the effect of report cards differed based on baseline ADR (interaction term $P$ value $=0.03$ ). Among physicians with a baseline ADR $<25 \%$, ADR increased 2.21 times after Year $1 \quad(P=0.003)$ and 2.17 times $(P=0.004)$ after Year 2 . Among physicians with a baseline $A D R \geq 25 \%$, ADR increased by $18 \%(P=0.10)$ after
Year 1 and $33 \%(P=0.01)$ after Year $2(\triangleright$ Table 4$)$ (see $\triangleright$ Supplement for model details).

The overall ADR was $40.6 \%$ for gastroenterologists and 32.0 $\%$ for general surgeons $(P<0.0001)$ ( $\downarrow$ Table 5$)$. Gastroenterologists were $52 \%$ more likely to detect an adenoma than a general surgeon on multivariate analysis (OR 1.52, $95 \% \mathrm{Cl} 1.28-1.81$ ) (see $\triangleright$ Supplement for model details). However, the change in ADR in Year 1 and Year 2 did not differ significantly by specialty (interaction term $P$ value $>0.05$ ).

\section{Discussion}

Reduction in colorectal cancer mortality from screening colonoscopy relies on identification and removal of precancerous polyps [21]. Accordingly, ADR has emerged as one of the most important quality metric in colonoscopy. In this study, we found that issuing annual performance report cards significantly improved ADR. On multivariate analysis, ADR improved by a striking $22 \%$ in Year 1 and $30 \%$ in Year 2 compared to baseline. The benefit of report cards depended on baseline ADR. Among 
- Table 3 Multivariate analysis ${ }^{1}$ of adenoma, polyp, advanced adenoma, and adenocarcinoma detection rates compared to baseline.

\begin{tabular}{|c|c|c|c|c|}
\hline & $\begin{array}{l}\text { Year } 1 \\
\text { OR }(95 \% \mathrm{Cl})\end{array}$ & $P$ value & $\begin{array}{l}\text { Year } 2 \\
\text { OR }(95 \% \mathrm{Cl})\end{array}$ & $P$ value \\
\hline Adenoma & $1.22(1.02-1.45)$ & 0.03 & $1.30(1.07-1.58)$ & 0.008 \\
\hline Polyp & $1.14(0.96-1.35)$ & 0.13 & $1.28(1.06-1.54)$ & 0.01 \\
\hline Advanced adenoma ${ }^{2}$ & $1.12(0.81-1.54)$ & 0.50 & $1.27(0.90-1.78)$ & 0.18 \\
\hline Adenocarcinoma & $1.30(0.48-3.53)$ & 0.61 & $2.04(0.75-5.58)$ & 0.16 \\
\hline
\end{tabular}

- Table 4 Improvement in adenoma detection rate by baseline adenoma detection rate ${ }^{1}$.

\begin{tabular}{|c|c|c|c|c|c|c|c|c|c|c|}
\hline \multirow[b]{2}{*}{$\begin{array}{l}\text { Baseline } \\
\text { ADR }\end{array}$} & \multicolumn{6}{|c|}{$\begin{array}{l}\text { Crude analysis } \\
\text { Adenoma detection rate (\%) }\end{array}$} & \multicolumn{4}{|c|}{$\begin{array}{l}\text { Multivariate analysis }{ }^{1} \\
\text { OR }(95 \% \mathrm{Cl}) \text { for adenoma detection compared to } \\
\text { baseline }\end{array}$} \\
\hline & Baseline & Year 1 & Year 2 & $\begin{array}{l}\text { Global } \\
\text { p-value }\end{array}$ & $\begin{array}{l}\text { P value }{ }^{2} \\
\text { (Year 1) }\end{array}$ & $\begin{array}{l}P \text { value }^{2} \\
\text { (Year 2) }\end{array}$ & Year 1 & Year 2 & $\begin{array}{l}P \text { value } \\
\text { (Year 1) }\end{array}$ & $\begin{array}{l}\text { Pvalue } \\
\text { (Year 2) }\end{array}$ \\
\hline$<25 \%$ & $\begin{array}{l}28 / 176 \\
(15.9 \%)\end{array}$ & $\begin{array}{l}67 / 254 \\
(26.4 \%)\end{array}$ & $\begin{array}{l}60 / 210 \\
(28.6 \%)\end{array}$ & 0.009 & 0.01 & 0.004 & $\begin{array}{l}2.21 \\
(1.32-3.71)\end{array}$ & $\begin{array}{l}2.17 \\
(1.28-3.68)\end{array}$ & 0.003 & 0.004 \\
\hline$\geq 25 \%$ & $\begin{array}{l}363 / 957 \\
(37.9 \%)\end{array}$ & $\begin{array}{l}395 / 918 \\
(43.0 \%)\end{array}$ & $\begin{array}{l}278 / 603 \\
(46.1 \%)\end{array}$ & 0.004 & 0.03 & 0.001 & $\begin{array}{l}1.18 \\
(0.97-1.43)\end{array}$ & $\begin{array}{l}1.33 \\
(1.08-1.66)\end{array}$ & 0.10 & 0.01 \\
\hline
\end{tabular}

- Table 5 Crude adenoma detection rate by specialty.

\begin{tabular}{|l|l|r|r|}
\hline \multicolumn{4}{|c|}{ Adenoma detection rate (\%) } \\
\hline & Gastroenterologist & General Surgeon & P value \\
\hline Baseline & $308 / 847(36.4 \%)$ & $83 / 286(29.0 \%)$ & 0.02 \\
\hline Year 1 & $350 / 842(41.6 \%)$ & $112 / 330(33.9 \%)$ & 0.02 \\
\hline Year 2 & $259 / 527(45.3 \%)$ & $79 / 241(32.8 \%)$ & 0.0009 \\
\hline Total & $917 / 2,216(40.6 \%)$ & $274 / 857(32.0 \%)$ & $<0.0001$ \\
\hline
\end{tabular}

those who were below recommended ADR at baseline ( $<25 \%)$, it improved 2.2 times by the end of Year 2. Accordingly, ADR in this group increased from $15.9 \%$ at baseline to $28.6 \%$ by the end of the study. Even among high performers who had a baseline $A D R \geq 25 \%, A D R$ improved by $33 \%$ after Year 2. Thus, our results support use of performance report cards to improve ADRs for all endoscopists.

In the absence of well-designed placebo-controlled, randomized clinical trials (RCTs), observational studies have been used to justify the effectiveness of performance report cards on improving ADR. Although our study is not the first to examine this intervention, it is the first to do so in a more rigorous manner. Past studies examining the effect of report cards on ADR or PDR either did not account for confounding variables [22-25] or controlled only for age and gender [26]. Given the strong association between variables such as patient age, gender, cecal intubation, and bowel preparation quality with ADR
$[15,16,20]$, failure to adjust for these factors may lead to erroneous conclusions. As an example, improvements in bowel preparation quality over time may have explained improvements in ADR observed independent of the impact of report cards in prior uncontrolled studies. This is particularly true since bowel preparation itself was a target for quality improvement during the period during which the prior studies were conducted. In our protocol, we prospectively measured potential confounders immediately after each colonoscopy and adjusted for them in a multivariate analysis, leading to a more accurate assessment of the impact of report cards on ADR. After controlling for confounders, we still found a significant improvement in ADR. To our knowledge, our study provides the most rigorous evidence for the effectiveness of performance report cards for improving ADR to date.

A recent RCT comparing performance report cards to an intensive quality improvement intervention bears mentioning [27]. In that study, colonoscopy screening center leaders who did not meet a target $25 \%$ ADR were randomized to receive either performance report cards or an intensive quality improvement initiative. This consisted of a 2-hour pretraining assessment, 2 days intensive hands-on training in the United Kingdom by expert colonoscopists, and further evaluation of the first 30 colonoscopies performed upon return to their home endoscopy center. Among endoscopists randomized to performance report cards, ADR increased by $2.3 \%$, which is lower than our observed $6.7 \%$ increase. Although direct comparisons between studies are difficult, we postulate several hypotheses 
to explain the difference. First, their patient population consisted of average-risk screening and was thus inherently different from ours. Second, endoscopists targeted in their study were those who did not meet a benchmark ADR $>25 \%$ and were mostly physicians in private practice. Third, the inherent study design was different as theirs was experimental and ours observational. Nonetheless, although the magnitudes of the effect estimates are different, it is reassuring that both studies demonstrated a significant improvement in ADR after the intervention.

In our study, there were no interventions other than performance report cards. Furthermore, report cards were confidential and not shared with anyone other than the endoscopists. There were no penalties, meetings with departmental chiefs, shaming, or other coercive actions to induce practice changes. Unlike other studies, the only motivation was the report card itself. We postulate that seeing one's performance objectively compared to others provided the introspection and motivation required for change.

Other than ADR, PDR improved over time as well. By the end of the study, the PDR had increased by $28 \%(P=0.01)$. However, we chose to focus on ADR as our primary outcome since PDR is subject to gaming. This is of particular importance for an intervention such as ours because it is possible for unscrupulous endoscopists to remove small hyperplastic polyps from the distal colon to improve this metric. There was also a trend towards improvement in detection of advanced adenomas although that did not reach statistical significance, likely due to the low event rate. Similarly, there were no more than 10 adenocarcinomas each year, making it unfeasible to draw reasonable conclusions about the effects of report cards on that outcome. Lastly, we found that ADR was affected by physician specialty. Prior studies using administrative data to determine interval colorectal cancer rates have reported differences between gastroenterologists, general surgeons, internists, and family physicians, although the results have been inconsistent [28-31]. In our study, all endoscopists used the same equipment on the same patient population and gastroenterologists were $52 \%$ more likely to detect an adenoma than were general surgeons. The reason for this discrepancy is beyond the scope of our study although differences in formal endoscopy training have been postulated previously [30].

The main limitation of our study is the lack of randomized allocation of the study intervention. Because this was a quality assurance intervention, all physicians were issued report cards during the study. Without randomization, there is a risk for biased results due to confounding variables. To address this possibility, we measured and adjusted for known confounders of ADR as reported in the literature. Nonetheless, there is still a risk for residual confounding by unmeasured factors. However, because the criteria for CCC screening did not change during the study period, it is unlikely to explain our findings. As a result, we believe our study provides a more robust effect estimate of the impact of performance report cards on ADR than previous studies that did not adjust for confounding. In our study, we chose to sample high-risk patients who were undergoing colonoscopy due to a history of colon cancer in a first-de- gree relative or who had a positive FOBT. We selected these patients because prior studies only focused on the general screening population and identifying a benchmark ADR for high-risk patients was previously identified as an unmet research need [15]. Nonetheless, there is no biological reason to expect that our intervention would be ineffective in the general screening population although the magnitude of improvement may differ, as it would when applied to different physicians, endoscopy units, and geographic locations. Lastly, although we did not record details regarding the bowel preparation itself (ie. type, dose, usage of split dosing, etc), our analysis adjusted for the quality of bowel preparation at the time of the procedure to provide an unbiased estimate of the treatment effect.

\section{Conclusion}

In conclusion, annual performance report cards increased ADR. The magnitude of the benefit was greatest in those who were below the threshold of $25 \%$ ADR although everyone benefited. Our results support institutional adoption of this inexpensive and non-invasive intervention to improve these quality metrics.

\section{Acknowledgements}

Dr. Sey is supported by an AMOSO Opportunities Grant. Dr. Asfaha is supported by a CIHR Clinician Scientist Phase II Award and CIHR Operating Grant.

\section{Competing interests}

None

\section{References}

[1] Howlader NNA, Krapcho M, Miller D et al. (ed). SEER Cancer Statistics Review, 1975-2013. Bethesda, MD: National Cancer Institute

[2] Snover DC. Update on the serrated pathway to colorectal carcinoma. Hum Pathol 2011; 42: 1 - 10

[3] Winawer S], Zauber AG, Ho MN. The National Polyp Study Workgroup. et al. Prevention of colorectal cancer by colonoscopic polypectomy. N Engl J Med 1993; 329: 1977 - 1981

[4] Zauber AG, Winawer S], O'Brien M]. Colonoscopic Polypectomy and Long-Term Prevention of Colorectal-Cancer Deaths. N Engl J Med 2012; 366: 687-696

[5] Baxter NN, Goldwasser MA, Paszat LF et al. Association of colonoscopy and death from colorectal cancer. Ann Intern Med 2009; 150: 1 - 8

[6] Cotterchio M, Manno M, Klar N et al. Colorectal screening is associated with reduced colorectal cancer risk: a case-control study within the population-based Ontario Familial Colorectal Cancer Registry. Cancer Causes Control 2005; 16: 865-875

[7] Brenner H, Chang-Claude J, Jansen L et al. Reduced risk of colorectal cancer up to 10 years after screening, surveillance, or diagnostic colonoscopy. Gastroenterology 2014; 146: 709-717

[8] Kahi CJ, Imperiale TF, Juliar BE et al. Effect of screening colonoscopy on colorectal cancer incidence and mortality. Clin Gastroenterol Hepatol 2009; 7: 770 - 775; quiz 711 
[9] Manser CN, Bachmann LM, Brunner J et al. Colonoscopy screening markedly reduces the occurrence of colon carcinomas and carcinoma-related death: a closed cohort study. Gastrointest Endosc 2012; 76: $110-117$

[10] Doubeni CA, Weinmann S, Adams K et al. Screening colonoscopy and risk for incident late-stage colorectal cancer diagnosis in average-risk adults: a nested case-control study. Ann Intern Med 2013; 158: 312 320

[11] Nishihara R, Wu K, Lochhead P et al. Long-term colorectal-cancer incidence and mortality after lower endoscopy. N Engl J Med 2013; 369: $1095-1105$

[12] Dominic OG, McGarrity T, Dignan M et al. American College of Gastroenterology Guidelines for Colorectal Cancer Screening 2008. Am J Gastroenterol 2009; 104: 2626-2627; author reply 2628-2629

[13] Kaminski MF, Regula J, Kraszewska E et al. Quality indicators for colonoscopy and the risk of interval cancer. N Engl J Med 2010; 362: $1795-1803$

[14] Corley DA, Jensen CD, Marks AR et al. Adenoma detection rate and risk of colorectal cancer and death. N Engl J Med 2014; 370: 1298 1306

[15] Rex DK, Schoenfeld PS, Cohen J et al. Quality indicators for colonoscopy. Am J Gastroenterol 2015; 110: 72 - 90

[16] Chen SC, Rex DK. Endoscopist can be more powerful than age and male gender in predicting adenoma detection at colonoscopy. Am J Gastroenterol 2007; 102: 856-861

[17] Shaukat A, Oancea C, Bond JH et al. Variation in detection of adenomas and polyps by colonoscopy and change over time with a performance improvement program. Clin Gastroenterol Hepatol 2009; 7: $1335-1340$

[18] Corley DA, Jensen CD, Marks AR. Can we improve adenoma detection rates? A systematic review of intervention studies Gastrointest Endosc 2011; 74: 656-665

[19] Bender R, Lange S. Adjusting for multiple testing-when and how? J Clin Epidemiol 2001; 54: 343-349

[20] Saltzman JR, Cash BD, Pasha SF et al. Bowel preparation before colonoscopy. Gastrointest Endosc 2015; 81: 781 - 794
[21] Brenner H, Chang-Claude ], Seiler CM et al. Protection from colorectal cancer after colonoscopy: a population-based, case-control study. Ann Intern Med 2011; 154: 22 - 30

[22] Lin OS, Kozarek RA, Arai A et al. The effect of periodic monitoring and feedback on screening colonoscopy withdrawal times, polyp detection rates, and patient satisfaction scores. Gastrointest Endosc 2010; 71: $1253-1259$

[23] Keswani RN, Yadlapati R, Gleason KM et al. Physician report cards and implementing standards of practice are both significantly associated with improved screening colonoscopy quality. Am J Gastroenterol 2015; 110: $1134-1139$

[24] Abdul-Baki H, Schoen RE, Dean K et al. Public reporting of colonoscopy quality is associated with an increase in endoscopist adenoma detection rate. Gastrointest Endosc 2015; 82: 676-682

[25] Imperiali G, Minoli G, Meucci GM et al. Effectiveness of a continuous quality improvement program on colonoscopy practice. Endoscopy 2007; 39: $314-318$

[26] Kahi C], Ballard D, Shah AS et al. Impact of a quarterly report card on colonoscopy quality measures. Gastrointest Endosc 2013; 77: 925 931

[27] Kaminski MF, Anderson J, Valori R et al. Leadership training to improve adenoma detection rate in screening colonoscopy: a randomised trial. Gut 2016; 65: 616-624

[28] Baxter NN, Sutradhar R, Forbes SS et al. Analysis of administrative data finds endoscopist quality measures associated with postcolonoscopy colorectal cancer. Gastroenterology 2011; 140: 65-72

[29] Bressler B, Paszat LF, Chen Z et al. Rates of new or missed colorectal cancers after colonoscopy and their risk factors: a population-based analysis. Gastroenterology 2007; 132: $96-102$

[30] Rabeneck L, Paszat LF, Saskin R. Endoscopist specialty is associated with incident colorectal cancer after a negative colonoscopy. Clin Gastroenterol Hepatol 2010; 8: 275-279

[31] Singh H, Nugent Z, Demers AA et al. Rate and predictors of early/ missed colorectal cancers after colonoscopy in Manitoba: a population-based study. Am J Gastroenterol 2010; 105: 2588-2596 


\section{Supplement}

- TableS1 Multivariate analysis of factors influencing adenoma detection rate.

\begin{tabular}{|c|c|c|}
\hline & Odds Ratio (95\% Cl) & p-value \\
\hline Year $1^{1}$ & $1.22(1.02-1.45)$ & 0.03 \\
\hline Year $2^{1}$ & $1.30(1.07-1.58)$ & 0.008 \\
\hline Gl specialty ${ }^{2}$ & $1.52(1.28-1.81)$ & $<0.001$ \\
\hline Age & $1.04(1.03-1.05)$ & $<0.001$ \\
\hline Male gender & $1.96(1.67-2.27)$ & $<0.001$ \\
\hline Positive FOBT & $1.20(0.99-1.44)$ & 0.05 \\
\hline Good bowel preparation ${ }^{3}$ & $4.32(1.96-9.51)$ & $<0.001$ \\
\hline Fair bowel preparation ${ }^{3}$ & $4.54(2.14-9.66)$ & $<0.001$ \\
\hline Cecal intubation & $6.78(3.30-13.91)$ & $<0.001$ \\
\hline \multicolumn{3}{|c|}{$\begin{array}{l}{ }^{1} \text { Compared to baseline } \\
{ }^{2} \text { Compared to general surgery } \\
{ }^{3} \text { Compared to poor bowel preparation }\end{array}$} \\
\hline
\end{tabular}

Table S2 Multivariate analysis of factors influencing polyp detection rate.

\begin{tabular}{|l|l|c|}
\hline & Odds Ratio (95\% CI) & P-value \\
\hline Year $1^{1}$ & $1.14(0.96-1.35)$ & 0.13 \\
\hline Year $2^{1}$ & $1.28(1.06-1.54)$ & 0.01 \\
\hline Gl specialty ${ }^{2}$ & $1.56(1.32-1.84)$ & $<0.001$ \\
\hline Age & $1.03(1.02-1.04)$ & $<0.0014$ \\
\hline Female gender & $0.54(0.47-0.63)$ & $<0.001$ \\
\hline Positive FOBT & $1.05(0.87-1.26)$ & 0.61 \\
\hline Good bowel preparation ${ }^{3}$ & $3.35(1.70-6.62)$ & $<0.001$ \\
\hline Fair bowel preparation & $3.58(1.89-6.79)$ & $<0.001$ \\
\hline \begin{tabular}{l} 
Cecal intubation \\
\hline${ }^{2}$ Compared to baseline \\
${ }^{3}$ Compared to general surgery
\end{tabular} & $5.61(3.09-10.20)$ & $<0.001$ \\
\hline
\end{tabular}

- Table S3 Multivariate analysis of high risk adenoma detection rate.

\begin{tabular}{|c|c|c|}
\hline & Odds Ratio (95\% Cl) & p-value \\
\hline Year $1^{1}$ & $1.12(0.81-1.54)$ & 0.50 \\
\hline Year $2^{1}$ & $1.27(0.90-1.78)$ & 0.18 \\
\hline Gl specialty ${ }^{2}$ & $1.30(0.93-1.82)$ & 0.13 \\
\hline Age & $1.04(1.02-1.05)$ & $<0.001$ \\
\hline Female gender & $0.55(0.42-0.72)$ & $<0.001$ \\
\hline Positive FOBT & $3.42(2.59-4.53)$ & $<0.001$ \\
\hline Good bowel preparation ${ }^{3}$ & $5.62(0.72-43.97)$ & 0.10 \\
\hline Fair bowel preparation ${ }^{3}$ & $7.66(1.03-57.13)$ & 0.05 \\
\hline Cecal intubation & $3.62(1.10-11.89)$ & 0.03 \\
\hline \multicolumn{3}{|c|}{$\begin{array}{l}{ }^{1} \text { Compared to baseline } \\
{ }^{2} \text { Compared to general surgery } \\
{ }^{3} \text { Compared to poor bowel preparation }\end{array}$} \\
\hline
\end{tabular}

- Table S4 Multivariate analysis of adenocarcinoma detection rate

\begin{tabular}{|c|c|c|}
\hline & Odds Ratio $(95 \% \mathrm{Cl})$ & p-value \\
\hline Year $1^{1}$ & $1.30(0.48-3.53)$ & 0.61 \\
\hline Year $2^{1}$ & $2.04(0.75-5.58)$ & 0.16 \\
\hline Gl specialty ${ }^{2}$ & $1.62(0.47-5.60)$ & 0.45 \\
\hline Age & $1.08(1.04-1.12)$ & $<0.001$ \\
\hline Female gender & $1.00(0.46-2.22)$ & 0.99 \\
\hline Positive FOBT & $12.28(4.07-37.05)$ & $<0.001$ \\
\hline Good bowel preparation ${ }^{3}$ & - & - \\
\hline Fair bowel preparation ${ }^{3}$ & - & - \\
\hline Cecal intubation & $0.33(0.10-1.08)$ & 0.07 \\
\hline \multicolumn{3}{|c|}{$\begin{array}{l}{ }^{1} \text { Compared to baseline } \\
{ }^{2} \text { Compared to general surgery } \\
{ }^{3} \text { Compared to poor bowel preparation }\end{array}$} \\
\hline
\end{tabular}


- Table S5 Multivariate analysis of adenoma detection rate for physicians with baseline ADR $<25 \%$.

\begin{tabular}{|c|c|c|}
\hline & Odds Ratio (95\% CI) & p-value \\
\hline Year $1^{1}$ & $2.21(1.32-3.71)$ & 0.003 \\
\hline Year $2^{1}$ & $2.17(1.28-3.68)$ & 0.004 \\
\hline GI specialty ${ }^{2}$ & $1.01(0.67-1.52)$ & 0.96 \\
\hline Age & $1.04(1.02-1.06)$ & $<0.001$ \\
\hline Female gender & $0.49(0.33-0.73)$ & $<0.001$ \\
\hline Positive FOBT & $1.60(1.00-2.55)$ & 0.05 \\
\hline Good bowel preparation ${ }^{3}$ & - & - \\
\hline Fair bowel preparation ${ }^{3}$ & - & - \\
\hline Cecal intubation & $5.47(1.18-25.33)$ & 0.03 \\
\hline \multicolumn{3}{|l|}{$\begin{array}{l}{ }^{1} \text { Compared to baseline } \\
{ }^{2} \text { Compared to general surgery } \\
{ }^{3} \text { Compared to poor bowel prep }\end{array}$} \\
\hline
\end{tabular}

- Table S6 Multivariate analysis of adenoma detection rate for physicians with baseline $A D R \geq 25 \%$.

\begin{tabular}{|c|c|c|}
\hline & Odds Ratio (95\% Cl) & p-value \\
\hline Year $1^{1}$ & $1.18(0.97-1.43)$ & 0.10 \\
\hline Year $2^{1}$ & $1.33(1.07-1.66)$ & 0.01 \\
\hline GI specialty ${ }^{2}$ & $1.42(1.16-1.75)$ & 0.001 \\
\hline Age & $1.04(1.03-1.05)$ & $<0.001$ \\
\hline Female gender & $0.50(0.42-0.59)$ & $<0.001$ \\
\hline Positive FOBT & $1.17(0.95-1.43)$ & 0.14 \\
\hline Good bowel preparation ${ }^{3}$ & $4.83(2.16-10.83)$ & $<0.001$ \\
\hline Fair bowel preparation ${ }^{3}$ & $5.03(2.34-10.82)$ & $<0.001$ \\
\hline Cecal intubation & $6.40(2.81-14.60)$ & $<0.001$ \\
\hline \multicolumn{3}{|c|}{$\begin{array}{l}{ }^{1} \text { Compared to baseline } \\
{ }^{2} \text { Compared to general surgery } \\
{ }^{3} \text { Compared to poor bowel preparation }\end{array}$} \\
\hline
\end{tabular}

